\title{
Community-building and promotion of technological excellence in molecular biophysics: the ARBRE-MOBIEU network
}

\author{
Patrick England ${ }^{1} \cdot$ Thomas A. Jowitt $^{2}$
}

Published online: 31 May 2021

(c) European Biophysical Societies' Association 2021

\section{Starting a community in molecular-scale biophysics}

The interface between Physics and Biology (Biophysics) has been, for centuries, a fantastically rich environment for scientific and technological innovation.

Molecular-scale biophysics is the study of biological systems at an intermediate level between atomic-resolution structural descriptions and cellular-scale observations. It sits at the crossroads of several areas of expertise (Fig. 1), and thus holds a strategic position, critical to cellular, molecular and structural biology, as well as to biomedicine, bio-production and biotechnology. It addresses essential questions on how active biomolecular assemblies form and function. These include insights into their architecture, folding, stability and dynamics, as well as into the energy and kinetics of their interactions, both at ensemble and single-event levels. It is a strongly interdisciplinary field involving physicists, biologists, chemists, as well as medical, bioinformatics and materials scientists.

The last decade has witnessed a remarkable expansion in the variety of molecular-scale biophysics technologies, utilising an ever-increasing number of physical phenomena to monitor molecular changes that allow scientists to dissect molecular behaviour and to answer biological problems. These technologies include hydrodynamics, advanced spectroscopies, calorimetry, fast and ultra-fast real-time bio-sensing, native mass spectrometry, and single-molecule

Patrick England

patrick.england@pasteur.fr

$\triangle$ Thomas A. Jowitt

thomas.a.jowitt@manchester.ac.uk

1 Molecular Biophysics Facility, Institut Pasteur, 25-28 rue du Docteur Roux, 75724 Paris cedex 15, France

2 Biomolecular Analysis Core Facility, Faculty of Biology Medicine and Health, University of Manchester, Oxford Road, Manchester M13 9PT, UK approaches such as atomic force microscopy and optical/ magnetic tweezers. Alongside instrumentation, there has been rapid advance in software and methods that allow for better understanding and interpretation of biophysical data. In parallel, the establishment of institutional biophysical characterization facilities, which provide access to cuttingedge instrumentation and employ technical specialists, have spearheaded many new developments in the field and led to higher quality published biophysical data.

Despite this, it was surprising that until 2014, there was no structured community network bringing together the molecular-scale biophysics technological specialists from core facilities, research laboratories and instrumentation/ technology developers. Molecular biophysics was only present as a support activity for structural biology studies within the INSTRUCT-ERIC (https://instruct-eric.org) and iNEXT (http://inext-eu.org) research infrastructures. The consequences were that the potential of the impressive arsenal of molecular-scale biophysical methodologies to tackle ambitious challenges in biological, medical and health research was far from fully exploited.

In 2013, we therefore decided to launch a Europewide coordinated initiative called ARBRE (Association of Resources for Biophysical Research in Europe; https:// arbre-mobieu.eu/), to synergize the expertise and technologies scattered over the continent. The focus of ARBRE is technological: it aims at improving the way biophysical research is performed, and at providing a platform for technical specialists to discuss instrumentation, methodologies and best practice. After a Kick-off meeting that took place in July 2014 in Institut Pasteur (Paris, France) with over 50 participants, we organised three meetings in 2015-2016, in London (Birkbeck), Dresden (CBG Max Plank Institute) and in Zaragoza (BIFI), where the number of participants amounted to close to 100 . 


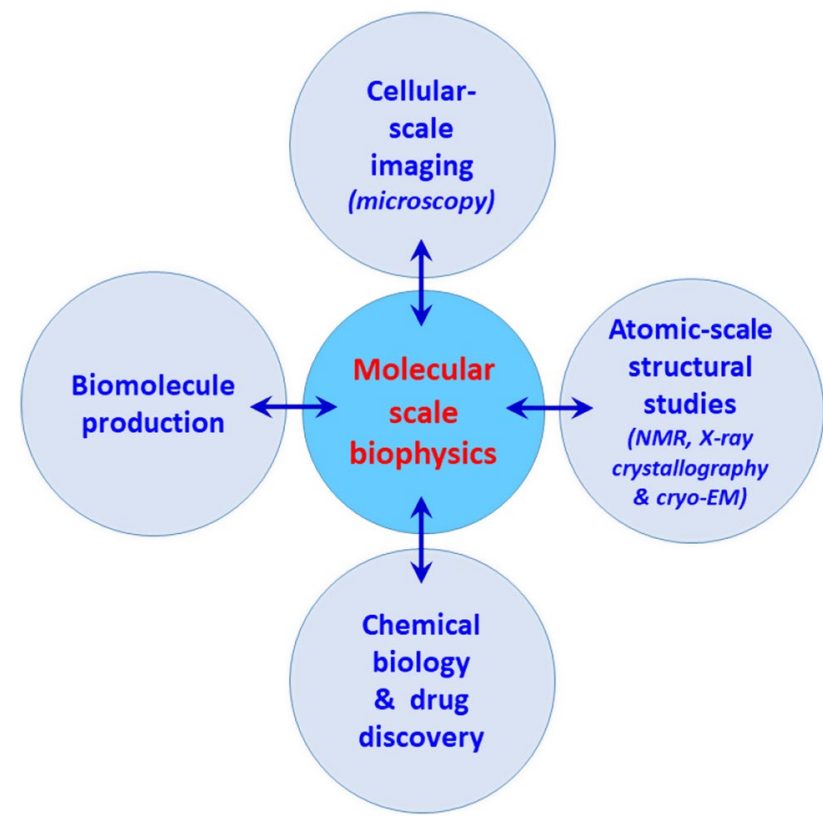

Fig. 1 Molecular-scale biophysics is positioned at a crucial multi-disciplinary crossroad

\section{The leverage effects of becoming a COST action}

It was decided that the most nurturing framework to consolidate our nascent initiative was COST (European Cooperation in Science and Technology; https://www.cost.eu/). A project was put together by a group of proposers from 17 countries, entitled "Between Atom and Cell: Integrating
Molecular Biophysics Approaches for Biology and Healthcare", with the acronym MOBIEU (Molecular-scale Biophysics in Europe). Our application was accepted, and the MOBIEU COST Action started in April 2016 in Brussels (https://www.cost.eu/actions/CA15126), chaired by Patrick England (Institut Pasteur, Paris) and vice-chaired by Thomas Jowitt (University of Manchester). COST funding allowed the fledgling network to become more established and structured, with the organization of 7 working groups dedicated to activities such as organizing meetings and training schools, implementing benchmarking studies, synergizing with other networks, outreaching to instrument developers, enabling transnational human mobility and putting together joint research grants (Fig. 2).

COST funding enabled a significant quantitative and qualitative increase of our networking activities. Their visibility progressively allowed the ARBRE-MOBIEU membership to reach a number of 360 scientists from 177 laboratories in 30 different countries (Fig. 3). 12 training schools were co-organised by ARBRE-MOBIEU members on a large variety of molecular-scale biophysics related scientific and technological topics (Velours et al. 2021). Our short-term scientific mission (STSM) programme was also highly popular, with a total of 52 transnational scientific visits funded, enabling mostly early career investigators to travel abroad to train and perform experiments for durations spanning from 1 week to 2 months.

The four plenary meetings of the network under the COST umbrella took place in Porto, Warsaw, Zagreb, and Prague, and were attended each time by over 150 delegates. They included sessions dedicated to novel instrumentation and methodologies, scientific breakthroughs and next
Fig. 2 ARBRE-MOBIEU organized its activities during its four years as COST Action around seven strongly interrelated working groups

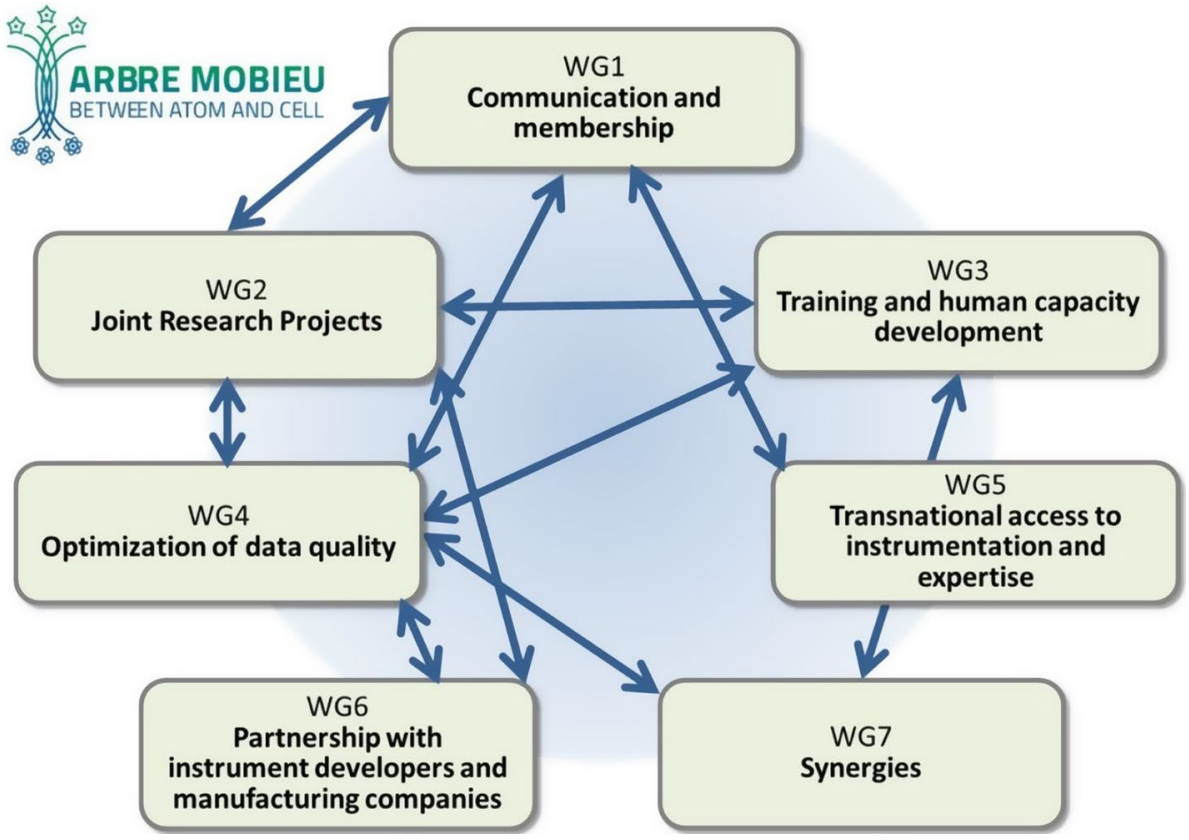


Fig. 3 Geographical extent of the ARBRE-MOBIEU network membership in 2020, at the end of its funding by COST

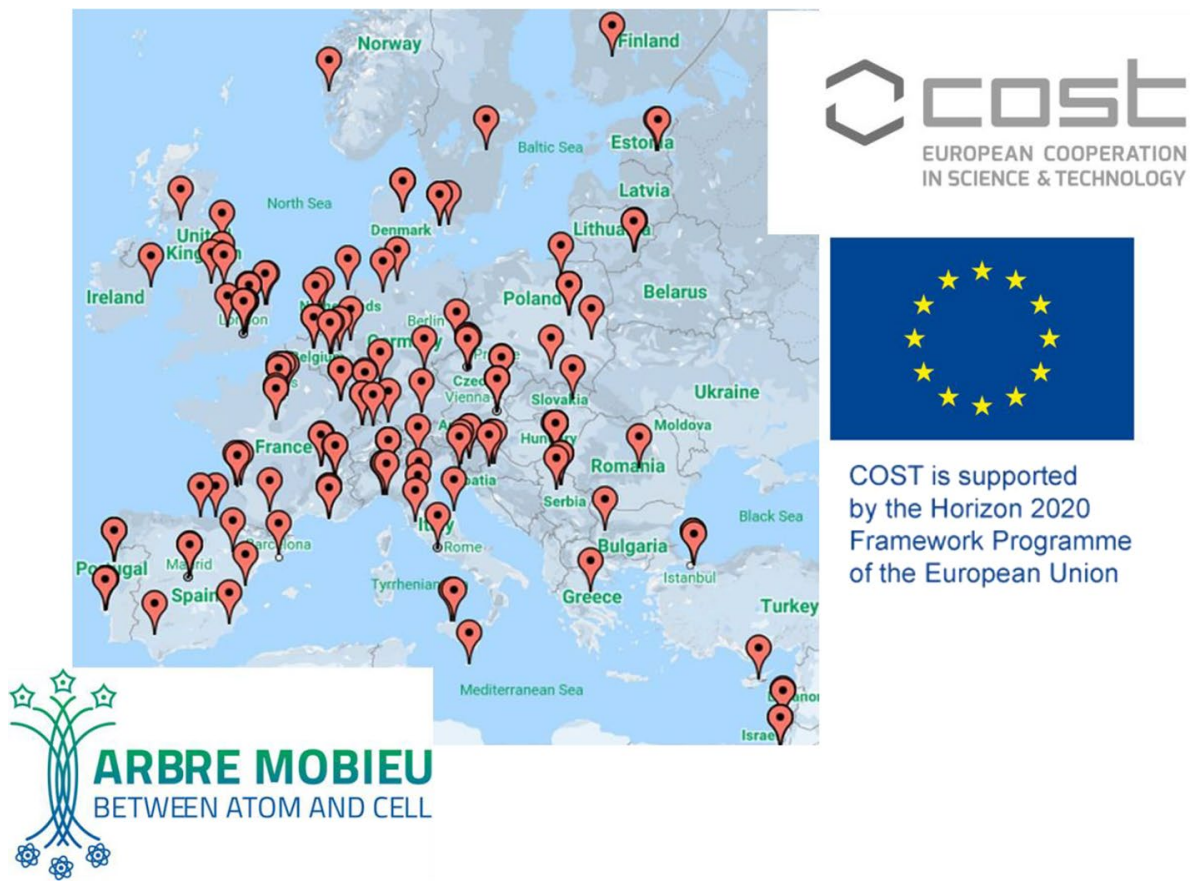

generation biophysics. The extremely positive feedback that we received, both from delegates and sponsors, clearly shows there is a need and a desire within the molecular biophysics community for technologically focussed meetings to continue. The ARBRE-MOBIEU meetings are of a vibrant, collegiate and informative nature and make an important contribution to the field.

Strong partnerships were developed with a number of European organizations, including the European Biophysical Societies Association (EBSA) and the INSTRUCT-ERIC infrastructure. These notably led to the organisation of a satellite meeting in 2017 (Dalla Serra et al. 2018) and a symposium in 2019 in the frame of EBSA congresses, and to two joint ARBRE-MOBIEU/INSTRUCT training schools in 2019 and 2020.

\section{Scientific outputs of the MOBIEU COST action}

A) Benchmarking, quality control and SOP's

The establishment of ARBRE-MOBIEU has created a previously inexistent niche for hundreds of technologically focussed biophysicists. This has already led to enhanced propagation of novel methodologies and collaboration between laboratories. The working group entitled 'Optimization of data quality' has been particularly popular and has focussed primarily on helping cross-laboratory teams (i) develop standard samples (Birchenough et al. 2021) which will be used in future training workshops and benchmarking studies, (ii) establish standard operating procedures (SOP's), (iii) carry out benchmarking studies and iv) define procedures for the optimisation of sample quality. The network has already generated SOP's across many instruments and methods, including enzymatic Activity inhibition assays (Smirnovienè et al. 2021), calibration of analytical ultracentrifuges (Zhao et al. 2021), isothermal titration calorimetry (Bastos and Velazquez-Campoy 2021), fluorescent thermal shift assays (Kazlauskas et al. 2021), microscale thermophoresis (MST) experiments (Sedivy 2021), Switchsense DRX instruments (Müller-Landau and Fernandez Varela 2021) and mass photometry ( $\mathrm{Wu}$ and Piszczek 2021). There have been two extremely successful benchmarking studies, one using the standard samples developed by the network examining the reproducibility and accuracy of MST instrumentation (López-Méndez et al. 2021a) and a multi-laboratory benchmark of ITC instrumentation using EDTA metal chelation (Velazquez-Campoy et al. 2021). The optimisation of sample quality is a big issue in the field, and has been a strong focus of ARBRE-MOBIEU along with the Protein Production and Purification Partnership in Europe (P4EU). Molecular Biophysics and protein production facilities are ideally placed to help standardise the procedures for assessing sample quality (Berrow et al. 2021) and aid in stability control with buffer screening approaches (Houser et al. 2021, Kellner et al. 2021).

B) Collaborative research projects.

ARBRE-MOBIEU has significantly enhanced collaboration between laboratories across Europe and has led to six collaborative research projects having been granted and 8 ongoing as of April 2020, as well as 16 scientific 
publications with multiple network members listed as authors. In addition, this special issue of the European Biophysics Journal includes a diversity of original research articles, describing for instance the secondary structure analysis of CueR (Balogh et al. 2021), the characterisation of the complex formed between Fep 1 and DNA (Miele et al. 2021) the analysis of the Dps-DNA interaction in Marinobacter hydrocarbonoclasticus (Jacinto et al. 2021), the characterisation of melanoma cell markers (Sobiepanek et al. 2021), the single-molecule study of cadherin bond rupture forces (VijiBabu et al. 2021), the study of a sulphur iron protein (Almeida et al. 2021) and that of a manganese superoxide dismutase variant (Bonetta et al. 2021). These are good examples of how the network is helping research groups enhance their understanding of biological systems through an improved use of biophysical approaches.

C) Instrumentation, methodological and data analysis developments.

ARBRE-MOBIEU has also played a huge role in establishing connections and collaborations with instrument developers. Many of the SOP's and benchmarking studies mentioned previously have had an input from the instrument manufacturers. But the network also led to the development of new and exciting methods and ways of using instrumentation, for example in the development of improved intrinsic viscosity measurements using the Viscosizer TD instrument (Brule et al. 2021), the complementary use of X-ray scattering and analytical ultracentrifugation to understand re-assembly of bacterial fimbriae (Solovyova et al. 2021), the improvement of FTIR spectra by partial deuteration of samples (De Meutter and Goormaghtigh 2021a) and the use of attenuated total reflection Fourier transform IR spectroscopy as a tool to characterize peptide/membrane interactions (Claro et al. 2021). The network has also contributed to the improvement of data analysis, for instance for evaluating FTIR spectra (De Meutter and Goormaghtigh 2021b), gaining increased information from MST experiments (LópezMéndez et al. 2021b) and accurately determining binding constant uncertainties in ITC experiments (Paketurytè et al 2021).

\section{Conclusions and future perspectives}

To summarize, the MOBIEU COST Action has, by all means, proved to be a perfect incubator for a starting community-building venture. Looking to the future and beyond this special issue of the European Biophysics Journal, the ARBRE-MOBIEU network will live on and thrive through two initiatives:

- The ARBRE association, that is currently being incorporated with headquarters in Lyon (France) and aims to

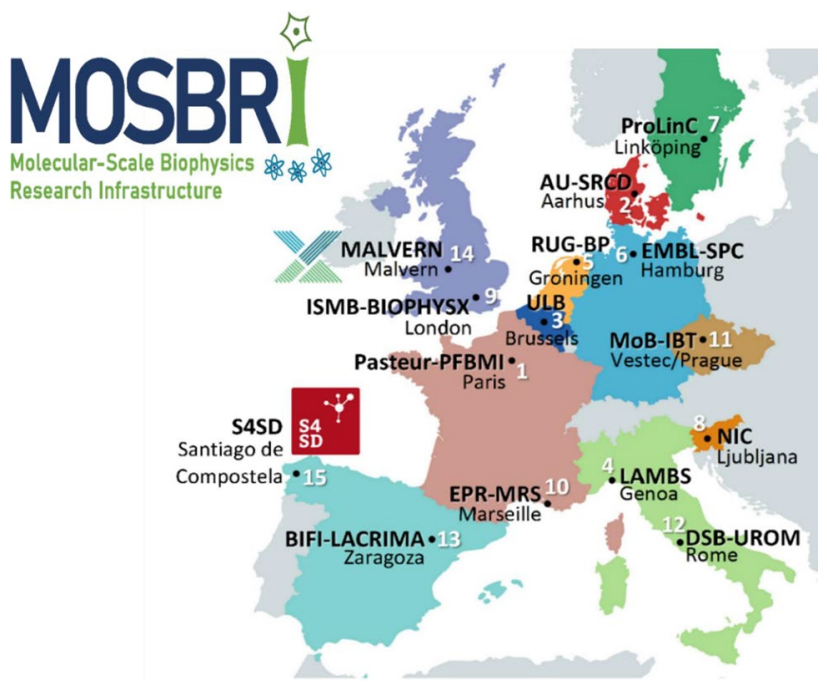

Fig. 4 Configuration of the MOSBRI consortium

perpetuate the inclusive and democratic spirit of COST Actions.

- The Molecular-Scale Biophysics Research Infrastructure (MOSBRI), funded by a Horizon 2020 INFRAIA grant from the European Commission. This $5 \mathrm{M} €$ project involves 15 partners from 11 countries, coordinated by Institut Pasteur (Paris, France) (Fig. 4). Starting on July 1st 2021 for 4 years, it will make a large scope of cuttingedge instrumentation and expertise available at no cost to scientists throughout Europe, and will allow the organisation of a variety of meetings, training schools and joint research activities (more information at www.mosbri.eu).

We thus foresee a bright future for the European molecular-scale biophysics community.

Acknowledgements All the articles of this special issue are based upon work from COST Action MOBIEU (CA15126; "Between Atom and Cell: Integrating Molecular Biophysics Approaches for Biology and Healthcare") supported by COST (European Cooperation in Science and Technology). COST (www.cost.eu) is a funding agency for research and innovation networks. Its Actions help connect research initiatives across Europe and enable scientists to grow their ideas by sharing them with their peers. This boosts their research, career and innovation.

\section{References}

Almeida AV, Jacinto JP, Guerra JPL et al (2021) Structural features and stability of apo- and holo-forms of a simple iron-sulfur protein. Eur Biophys J. https://doi.org/10.1007/s00249-021-01546-0

Balogh RK, Németh E, Jones NC et al (2021) A study on the secondary structure of the metalloregulatory protein CueR: effect of $\mathrm{pH}$, metal ions and DNA. Eur Biophys J. https://doi.org/10.1007/ s00249-021-01539-z 
Bastos M, Velazquez-Campoy A (2021) Isothermal titration calorimetry (ITC): a standard operating procedure (SOP). Eur Biophys J. https://doi.org/10.1007/s00249-021-01509-5

Berrow N, de Marco A, Lebendiker M et al (2021) Quality control of purified proteins to improve data quality and reproducibility: results from a large-scale survey. Eur Biophys J. https://doi.org/ 10.1007/s00249-021-01528-2

Birchenough HL, Nivia HDR, Jowitt TA (2021) Interaction standards for biophysics: anti-lysozyme nanobodies. Eur Biophys J. https:// doi.org/10.1007/s00249-021-01524-6

Bonetta R, Hunter GJ, Trinh CH et al (2021) Substitution of histidine 30 by asparagine in manganese superoxide dismutase alters biophysical properties and supports proliferation in a K562 leukemia cell line. Eur Biophys J. https://doi.org/10.1007/ s00249-021-01544-2

Brûlé S, Leroux R, England P et al (2021) Protein intrinsic viscosity determination with the Viscosizer TD instrument: reaching beyond the initially expected applications. Eur Biophys J. https:// doi.org/10.1007/s00249-020-01492-3

Claro B, Goormaghtigh E, Bastos M (2021) Attenuated total reflectionFourier transform infrared spectroscopy: a tool to characterize antimicrobial cyclic peptide-membrane interactions. Eur Biophys J. https://doi.org/10.1007/s00249-020-01495-0

Dalla Serra M, Gilbert RJC, Matagne A et al. Biophysical approaches to protein folding and disease, a satellite meeting to the IUPABEBSA congress. Eur Biophys J 47: 95-96 (2018). https://doi.org/ 10.1007/s00249-018-1288-0

De Meutter J, Goormaghtigh E (2021a) Evaluation of protein secondary structure from FTIR spectra improved after partial deuteration. Eur Biophys J. https://doi.org/10.1007/s00249-021-01502-y

De Meutter J, Goormaghtigh E (2021b) Amino acid side chain contribution to protein FTIR spectra: impact on secondary structure evaluation. Eur Biophys J. https://doi.org/10.1007/ s00249-021-01507-7

Houser J, Kosourova J, Kubickova M et al (2021) Development of 48-condition buffer screen for protein stability assessment. Eur Biophys J. https://doi.org/10.1007/s00249-021-01497-6

Jacinto JP, Penas D, Guerra JPL et al (2021) Dps-DNA interaction in Marinobacter hydrocarbonoclasticus protein: effect of a single-charge alteration. Eur Biophys J. https://doi.org/10.1007/ s00249-021-01538-0

Kazlauskas E, Petrauskas V, Paketurytė V et al (2021) Standard operating procedure for fluorescent thermal shift assay (FTSA) for determination of protein-ligand binding and protein stability. Eur Biophys J. https://doi.org/10.1007/s00249-021-01537-1

Kellner R, Malempré R, Vandenameele J et al (2021) Protein formulation through automated screening of $\mathrm{pH}$ and buffer conditions, using the Robotein ${ }^{\circledR}$ high throughput facility. Eur Biophys J. https://doi.org/10.1007/s00249-021-01510-y

López-Méndez B, Baron B, Brautigam CA et al (2021a) Reproducibility and accuracy of microscale thermophoresis in the NanoTemper Monolith: a multi laboratory benchmark study. Eur Biophys J. https://doi.org/10.1007/s00249-021-01532-6
López-Méndez B, Uebel S, Lundgren LP et al (2021b) Microscale thermophoresis and additional effects measured in nanotemper monolith instruments. Eur Biophys J. https://doi.org/10.1007/ s00249-021-01529-1

Miele AE, Cervoni L, Le Roy A et al (2021) Biophysical characterization of the complex between the iron-responsive transcription factor Fep1 and DNA. Eur Biophys J. https://doi.org/10.1007/ s00249-020-01489-y

Müller-Landau H, Varela PF (2021) Standard operation procedure for switchSENSE DRX systems. Eur Biophys J. https://doi.org/10. 1007/s00249-021-01519-3

Paketurytė V, Petrauskas V, Zubrienė A et al (2021) Uncertainty in protein-ligand binding constants: asymmetric confidence intervals versus standard errors. Eur Biophys J. https://doi.org/10.1007/ s00249-021-01518-4

Sedivy A (2021) Standard operating procedure for nanotemper monolith measurements. Eur Biophys J. https://doi.org/10.1007/ s00249-021-01534-4

Smirnovienė J, Baranauskienė L, Zubrienė A et al (2021) A standard operating procedure for an enzymatic activity inhibition assay. Eur Biophys J. https://doi.org/10.1007/s00249-021-01530-8

Sobiepanek A, Paone A, Cutruzzolà F et al (2021) Biophysical characterization of melanoma cell phenotype markers during metastatic progression. Eur Biophys J. https://doi.org/10.1007/ s00249-021-01514-8

Solovyova AS, Peters DT, Dura G et al (2021) Probing the oligomeric re-assembling of bacterial fimbriae in vitro: a small-angle $\mathrm{X}$-ray scattering and analytical ultracentrifugation study. Eur Biophys J. https://doi.org/10.1007/s00249-021-01543-3

Velazquez-Campoy A, Claro B, Abian O et al (2021) A multi-laboratory benchmark study of isothermal titration calorimetry (ITC) using $\mathrm{Ca}^{2+}$ and $\mathrm{Mg}^{2+}$ binding to EDTA. Eur Biophys J. https:// doi.org/10.1007/s00249-021-01523-7

Velours C, Aumont-Nicaise M, Uebel S et al (2021) Macromolecular interactions in vitro, comparing classical and novel approaches. Eur Biophys J. https://doi.org/10.1007/s00249-021-01517-5

VijiBabu PK, Mirastschijski U, Belge G et al (2021) Homophilic and heterophilic cadherin bond rupture forces in homo- or hetero-cellular systems measured by AFM-based single-cell force spectroscopy. Eur Biophys J. https://doi.org/10.1007/s00249-021-01536-2

Wu D, Piszczek G (2021) Standard protocol for mass photometry experiments. Eur Biophys J. https://doi.org/10.1007/ s00249-021-01513-9

Zhao H, Nguyen A, To SC et al (2021) Calibrating analytical ultracentrifuges. Eur Biophys J. https://doi.org/10.1007/ s00249-020-01485-2

Publisher's Note Springer Nature remains neutral with regard to jurisdictional claims in published maps and institutional affiliations. 